\title{
Panen dan Penanganan Pascapanen Asparagus umbellatus, Monstera, dan Philodendron di Naaldjwik, Belanda Selatan, Belanda
}

\author{
Harvesting and Post Harvest Handling of Asparagus umbellatus, Monstera, and Philodendron at \\ Naaldjwik, South Holland, Holland
}

\section{Asti Kusriyanti dan Darda Efendi*}

Departemen Agronomi dan Hortikultura, Fakultas Pertanian, Institut Pertanian Bogor (Bogor Agricultural University), Jl. Meranti, Kampus IPB Darmaga, Bogor 16680, Indonesia

Telp. \& Faks.62-251-8629353 e-mail agrohort@apps.ipb.ac.id

*Penulis Korespondensi : dardaefendi@ gmail.com

Disetujui : 31 Oktober 2018 / Published Online 20 Mei 2019

\begin{abstract}
The research activity was conducted in a greenhouse at Naaldjwik from 26th of February until 25 of May 2018. This research aimed to improve student ability, knowledge and skills on aspects of Asparagus umbellatus, Monstera and Philodendron cut foliage cultivation generally and specifically to learn the harvest and postharvest at Naaldjwik. The method used was direct method and indirect method. The direct method was conducted by direct observation in the field and following all of technical activities of leaf ornamental plants cultivation from planting until postharvest. Mean while, the indirect method was conducted by gathering and learning of secondary data such as company archieves, company reports and literature study. The cultivation process, harvest and postharvest handling of leaf ornamental plants have been done as well. It is shown by optimum production result, that is more than $99 \%$ sold product and less than $0.1 \%$ production losses.
\end{abstract}

Keywords: cut foliage, leaf ornamental plants, production

\begin{abstract}
ABSTRAK
Kegiatan penelitian dilaksanakan di sebuah greenhouse di Naaldjwik mulai 26 Februari sampai dengan 25 Mei 2018. Kegiatan penelitian bertujuan untuk mempelajari proses penanganan panen dan pascapanen komoditas daun potong Asparagus umbellatus, Monstera, dan Philodendron. Metode yang digunakan adalah metode langsung dan tidak langsung. Metode langsung dilaksanakan dengan melakukan pengamatan secara langsung di lapang serta mengikuti semua kegiatan teknis budidaya tanaman hias daun mulai dari penanaman sampai dengan pascapanen. Penanganan panen dan pascapanen tanaman hias daun sudah dilakukan dengan baik. Hal tersebut ditunjukkan dengan hasil produksi yang optimum, mencapai lebih dari $99 \%$ produksi terjual dengan kehilangan hasil kurang dari $0.1 \%$.
\end{abstract}

Kata kunci: daun potong, produksi, tanaman hias daun 


\section{PENDAHULUAN}

Tanaman hias daun merupakan tanaman yang memiliki bentuk daun, warna, dan struktur menarik. Tanaman hias daun disukai oleh konsumen karena keindahan bentuk dan variasi warna, kemulusan dan ketegaran daun serta kekompakan susunan daun (Tono, 2002). Tanaman hias daun mempunyai dua fungsi, helaian daunnya yang dapat dijadikan sebagai filler untuk mengisi rangkaian bunga (daun potong) dan dapat juga dijadikan sebagai tanaman hias dalam pot.

Daun Potong merupakan bagian tanaman yang memiliki karakter estetika (indah) yang dipanen dari tanaman induk untuk dimanfaatkan atau dijual. Beberapa jenis daun potong yang umum dibudidayakan secara komersial diantaranya Asparagus, Monstera, dan Philodendron. Asparagus termasuk dalam famili Liliaceae. Tanaman ini dapat tumbuh bertahuntahun dan berkembang secara alami dengan mudah dan cepat. Daun yang terlihat berwarna hijau sebenarnya bukanlah daun melainkan ranting. Daun semu itu biasa disebut dengan cladode atau cladophyl (Winda, 2006). Monstera dan Philodendron merupakan genus dari famili Araceae yang memiliki kurang lebih 25 spesies jenis Monstera dan 200 spesies jenis Philodendron. Monstera memiliki daun yang lebar dengan pola belahan pada helaian (splitleaf), halus dan mengkilap dapat membuat visualisasi dasar (background filler) pada rangkaian bunga (BALITHI, 2008). Philodendron memiliki keragaman bentuk daun seperti hati, lonjong berujung lancip, menjari dan memiliki warna daun bermacam-macam yang mampu menampilkan pesona keindahan (Siong dan Budiana, 2008).

Belanda adalah negara empat musim dengan luas wilayah yang kecil. Luas wilayah di Belanda adalah $41864 \mathrm{~km}^{2}$ (BBC, 2014). Belanda merupakan pusat perdagangan tanaman hias daun di Eropa. Pada tahun 2015, Belanda mengekspor \$239 juta tanaman hias daun untuk keperluan rangkaian bunga, terutama ke Jerman, Perancis, dan Inggris. Pasar non-UE yang paling penting adalah Rusia (GAIN, 2016). Negara-negara subtropis terutama Belanda, telah membudidayakan tanaman hias daun di dalam greenhouse dan telah berkembang menjadi suatu industri yang menguntungkan sebagai pelengkap rangkaian bunga atau filler. Teknik budidaya dalam greenhouse yang diterapkan di Belanda mampu memproduksi tanaman hias daun tropis dengan produktivitas maksimum dan kualitas yang tinggi (Roseita, 2012). Greenhouse sangat penting dalam mendukung produksi pertanian dikarenakan kondisi lingkungan, cahaya, kelembaban, suhu, dan irigasi yang dapat dikendalikan.

Teknik panen dan penanganan pascapanen yang tepat akan mengurangi kehilangan hasil, meningkatkan mutu dan kualitas serta meningkatkan nilai jual daun potong. Hal ini sangat ditentukan oleh tindakan budidaya selama masa produksi, teknik pemanenan dan penanganan pascapanen. Tujuan umum kegiatan penelitian ini adalah meningkatkan kemampuan teknis mahasiswa dalam aspek budidaya tanaman hias daun Asparagus umbellatus, Monstera, dan Philodendron. Tujuan khusus kegiatan penelitian ini adalah mempelajari proses pengelolaan panen dan pascapanen tanaman hias daun Asparagus umbellatus, Monstera, dan Philodendron.

\section{BAHAN DAN METODE}

Kegiatan penelitian dilaksanakan di sebuah greenhouse, bertempat di Naaldjwik Provinsi Belanda Selatan pada tanggal 26 Februari - 25 Mei 2018. Koordinat lokasi penelitian 51'97'67'LS- 4'20'79'" BT dengan ketinggian rata-rata $0 \mathrm{~m}$ di atas permukaan laut.

Kegiatan penelitian dilaksanakan dengan dua metode, yaitu metode langsung dan tidak langsung. Metode langsung dilaksanakan dengan melakukan pengamatan secara langsung di lapang serta mengikuti semua kegiatan teknis budidaya tanaman hias daun mulai dari penanaman pada tanaman Asparagus umbellatus sampai dengan pascapanen. Metode tidak langsung dilaksanakan dengan memperoleh dan mempelajari data sekunder berupa arsip, laporan dari pengelola greenhouse dan studi pustaka. Kegiatan selama penelitian terdiri atas satu aspek utama, yaitu aspek teknis. Aspek teknis mencakup persiapan media tanam, bahan tanam, penanaman, pemeliharaan tanaman, pengendalian hama dan penyakit, serta pemasaran.

Data yang telah dikumpulkan berupa data primer dan data sekunder. Data primer merupakan data hasil pengamatan secara langsung di lapangan serta melakukan diskusi dan wawancara dengan pengelola greenhouse.

Tanaman hias daun yang diamati dipilih tiga tanamam dari lima tanaman yang dibudidayakan di greenhouse, yaitu Asparagus umbellatus, Monstera, dan Philodendron. Data primer diperoleh dari hasil pengamatan langsung mulai dari pertumbuhan tanaman hingga penanganan pascapanen meliputi:

\section{Pra panen}

Pengamatan pertumbuhan tanaman hias daun 
dihitung dengan beberapa parameter yaitu, lebar daun, tinggi tangkai daun, panjang daun dan cabang pada tangkai daun tanaman Asparagus umbellatus, pengamatan karakter kuantitatif dilakukan dengan mengambil lima tanaman contoh secara acak pada beberapa baris yang terdapat dalam blok untuk tanaman hias daun Asparagus umbellatus, Monstera, dan Philodendron yang diamati sebanyak tiga ulangan.

2. Panen

Pengamatan panen dilakukan dengan mengamati kriteria panen, tingkat kematangan daun siap untuk dipanen, teknik pemanenan yang diterapkan oleh perusahaan, dan menghitung perbedaan jumlah tanaman yang dipanen dengan rata-rata standar produksi perusahaan per hari pada ketiga komoditas yaitu Asparagus umbellatus, Monstera, dan Philodendron.

\section{Pascapanen}

Pengamatan pascapanen dilakukan dengan mengamati kriteria daun potong pada ketiga komoditas yang diamati saat penyortiran, dan pengelompokkan daun potong berdasarkan ukuran yang sudah ditentukan oleh perusahaan.

Data dan informasi yang diperoleh selama penelitian dinalisis secara deskriptif dan kuantitatif. Data primer dianalisis dengan menggunakan rata-rata dan standar deviasi serta persentase, sedangkan data sekunder dianaliisis dengan menggunakan analisis deskriptif

\section{HASIL DAN PEMBAHASAN}

\section{Kondisi Umum}

Belanda termasuk negara yang beriklim subtropis. Negara ini memiliki empat musim yaitu musim semi, musim panas, musim gugur, dan musim dingin. Klasifikasi iklim Koppen dan Geiger menunjukkan bahwa lokasi greenhouse berada pada kelompok iklim maritim $\mathrm{Cfb}$ yaitu iklim sedang berhujan (Kottek et al., 2006). Data rata-rata total curah hujan di Naaldjwik dari tahun 2010 hingga tahun 2016 adalah $904.314 \mathrm{~mm}$ per tahun dengan rata-rata 190 hari hujan. Rata-rata curah hujan bulanan adalah $75.34 \mathrm{~mm}$ dengan curah hujan tertinggi berada pada bulan Agustus serta curah hujan terendah pada bulan April. Suhu harian di Naaldjwik berkisar $-4.4-26{ }^{\circ} \mathrm{C}$ dengan suhu terendah dapat mencapai $-4.4{ }^{0} \mathrm{C}$ dan suhu tertinggi mencapai $26{ }^{\circ} \mathrm{C}$. Suhu hangat berada pada kisaran bulan Juni hingga September, dan suhu dingin bekisar pada bulan November hingga Maret. Suhu tertinggi sepanjang tahun berkisar pada bulan Juli hingga Agustus, dan suhu terdingin sepanjang tahun berkisar pada bulan Januari hingga Februari. Kelembaban relatif sepanjang tahun 2017 berkisar antara 26-99\% (Weerstation Westland, 2017). Tanah di Naaldjwik merupakan tipe tanah young marine clay dengan kandungan bahan organik sekitar 5\% dan memiliki pH berkisar 6.3-6.7 (Heesen, 2011).

Umur tanaman yang digunakan sebagai bahan penelitian; Asparagus umbellatus sudah sekitar 11 tahun, sedangkan untuk tanaman Monstera berumur sekitar 15 tahun, dan untuk Philodendron berumur sekitar 5 tahun. Total waktu yang dibutuhkan untuk budidaya Asparagus umbellatus adalah 16 bulan dari mulai bibit hingga tanaman siap untuk dipanen, sedangkan untuk budidaya tanaman Monstera membutuhkan waktu 5 bulan dari mulai bibit hingga tanaman siap untuk dipanen, dan untuk tanaman Philodendron sendiri membutuhkan waktu 8 bulan dari mulai bibit hingga tanaman siap panen.

\section{Pra panen}

Kondisi prapanen yang sangat menentukan kualitas daun potong adalah pertumbuhannya selama di lapangan. Faktor eksternal selama budidaya tanaman hias harus diperhatikan karena dapat mempengaruhi kualitas hasil panen tersebut. Cahaya, suhu dan kelembaban merupakan unsur iklim atau cuaca yang berperan sebagai faktor tumbuh dalam menghasilkan tanaman dengan kualitas baik (Santoso, 2003). Data rata-rata pertumbuhan pada tanamam hias daun dapat dilihat pada Tabel 1, 2, 3 .

Tabel 1. Rata-rata pertumbuhan tanaman hias daun Asparagus umbellatus

\begin{tabular}{lcccc}
\hline Paramete & \multicolumn{4}{c}{ Pengamatan Minggu Ke- } \\
\cline { 2 - 5 }$r$ & 1 & 2 & 3 & 4 \\
\hline $\begin{array}{l}\text { Tinggi } \\
\text { tangkai } \\
\text { daun }\end{array}$ & $44.3 \pm 15.3$ & $55.2 \pm 15.6$ & $61 \pm 15.7$ & $69 \pm 13.3$ \\
$\begin{array}{l}\text { Cabang } \\
\text { tangkai } \\
\text { daun }\end{array}$ & $9.2 \pm 6.5$ & $14.4 \pm 4.7$ & $16.6 \pm 4.5$ & $18.9 \pm 4.2$ \\
\hline
\end{tabular}


Tabel 2. Rata-rata pertumbuhan tanaman hias daun Monstera

\begin{tabular}{lcccccl}
\hline \multirow{2}{*}{ Parameter } & \multicolumn{7}{c}{ Pengamatan Minggu Ke- } \\
\cline { 2 - 7 } & 1 & 2 & 3 & 4 & 5 & 6 \\
\hline Tinggi tangkai daun & $21.06 \pm 5.11$ & $23.2 \pm 5$ & $25.2 \pm 5.32$ & $27.14 \pm 5.3$ & $28.35 \pm 5.4$ & $30 \pm 5.5$ \\
Lebar daun & $5.46 \pm 2.35$ & $6.7 \pm 2.54$ & $7.6 \pm 2.77$ & $8.5 \pm 3$ & $9.5 \pm 3.4$ & $11.57 \pm 3.6$ \\
Panjang daun & $8.4 \pm 2.47$ & $9.9 \pm 3$ & $11.2 \pm 3.19$ & $13 \pm 3.17$ & $13.8 \pm 3.2$ & $15.6 \pm 3.7$ \\
\hline
\end{tabular}

Tabel 3. Rata-rata pertumbuhan tanaman hias daun Philodendron

\begin{tabular}{lcccccc}
\hline \multirow{2}{*}{ Parameter } & \multicolumn{7}{c}{ Pengamatan Minggu Ke- } \\
\cline { 2 - 7 } & 1 & 2 & \multicolumn{1}{c}{3} & 4 & \multicolumn{1}{c}{5} & \multicolumn{1}{c}{6} \\
Tinggi tangkai & $16.9 \pm 5.63$ & $23.26 \pm 5.3$ & $25.7 \pm 5.5$ & $27.9 \pm 5$ & $30.7 \pm 5.7$ & $32.8 \pm 4.9$ \\
daun & & & & & & \\
Lebar daun & $3.93 \pm 1.03$ & $4.62 \pm 1.23$ & $4.7 \pm 1.33$ & $5.1 \pm 1.3$ & $5.53 \pm 1.21$ & $6.56 \pm 1.03$ \\
Panjang daun & $14.3 \pm 5.25$ & $17.26 \pm 5.3$ & $18.6 \pm 5.61$ & $20.4 \pm 5.7$ & $23.2 \pm 6.13$ & $25.0 \pm 5.9$ \\
\hline
\end{tabular}

Tanaman hias daun mengalami pertumbuhan yang berbeda pada ketiga komoditas yang diamati. Berdasarkan hasil pengamatan rata-rata parameter, dapat dilihat bahwa pertumbuhan tanaman semakin meningkat mulai minggu pertama pengamatan hingga minggu terakhir pengamatan. Tanaman Asparagus umbellatus mengalami pertumbuhan yang sangat cepat setiap minggunya dibandingkan dengan tanaman Monstera dan Philodendron. Faktor lingkungan sangat berperan penting untuk proses pertumbuhan tanaman. Suhu dan kelembaban dijaga seoptimum mungkin untuk pertumbuhan tanamam hias daun di greenhouse. Kondisi kelembaban dan suhu tersebut mendukung aktivitas pemanjangan sel-sel. Sel-sel cepat mencapai ukuran maksimum sehingga pertumbuhan semakin cepat (Talbott et al., 2003).

Tanaman hias daun yang dibudidayakan di dalam greenhouse ini memiliki kebutuhan suhu dan kelembaban yang berbeda pada masingmasing komoditas (Tabel 4). Kebutuhan suhu dibedakan antara siang hari dan malam harinya. Suhu dijaga minimal $16{ }^{\circ} \mathrm{C}$ pada malam hari dan $18{ }^{\circ} \mathrm{C}$ pada siang hari. Pengaturan suhu dilakukan dengan sistem pemanas yang disebut boiler, berfungsi untuk menciptakan kondisi pertumbuhan yang lebih baik agar tanaman dapat tumbuh dan berkembang dengan menjaga suhu udara di dalam greenhouse pada tingkat yang tepat untuk pertumbuhan optimal (Vourdoubas, 2015).

Tabel 4. Kondisi lingkungan optimum pada tanaman hias daun di dalam greenhouse

\begin{tabular}{lccc}
\hline Tanaman & \multicolumn{2}{c}{ Suhu $\left({ }^{\circ} \mathrm{C}\right)$} & $\begin{array}{c}\text { Kelembaban } \\
(\%)\end{array}$ \\
\cline { 2 - 3 } & Siang & Malam & $(18$ \\
\hline Asparagus & $20-30$ & $18-80$ \\
Umbellatus & & & \\
Monstera & $18-29$ & 16 & $65-70$ \\
\hline
\end{tabular}

\begin{tabular}{lccc}
\hline Philodendron & $24-29$ & $16-18$ & $65-80$ \\
\hline Keterangan : Data Perusahaan Kwekerij Figaro Tahun \\
2018
\end{tabular}

Kondisi lingkungan optimum pada ketiga komoditas berbeda, hal ini disebabkan karena setiap tanaman memiliki batas suhu optimum untuk pertumbuhannya, begitu juga dengan besarnya nilai kelembaban yang berpengaruh, sehingga perlu dikendalikan besarnya nilai suhu dan kelembaban dalam greenhouse. Suhu di dalam greenhouse dijaga minimal sebesar 16-18 ${ }^{\circ} \mathrm{C}$ pada musim dingin, sedangkan pada musim semi suhu di greenhouse sebesar $20-27^{\circ} \mathrm{C}$, pada musim panas suhu sebesar $21-30{ }^{\circ} \mathrm{C}$, dan pada musim gugur suhu di greenhouse sebesar 19$21^{\circ} \mathrm{C}$ dengan kelembaban sekitar 64-80\%. Mengatur serta menjaga suhu dan kelembaban di dalam greenhouse pada tanaman sangat penting untuk pertumbuhan tanaman agar tumbuh seoptimal mungkin.

\section{Panen dan Pascapanen}

Teknik pemanenan yang diterapkan oleh perusahaan yaitu dengan cara manual, memotong bagian ujung tangkai daun menggunakan pisau dan gunting. Gunting dipakai untuk memanen tanaman hias daun Asparagus umbellatus karena tanaman ini memiliki batang yang kokoh, sedangkan pisau dipakai untuk memanen tanaman Philodendron dan Monstera karena tanaman ini memiliki batang yang lunak.

Standar mutu untuk ketiga komoditas tanaman yang diamati di perusahaan Kwekerij Figaro mengikuti standar mutu yang ditetapkan oleh The Dutch Flower Auctions Association atau Vereniging van Bloemenveilingen in Nederland (VBN). Tanaman dibedakan berdasarkan standar kriteria untuk pemanenan dan pascapanen (Tabel 5). Standar mutu utama daun potong yaitu meliputi panjang tangkai daun minimum dan stadia kematangan daun yang 
ditunjukkan pada daun berwarna hijau tua. Standar mutu penunjang lainnya diantaranya tidak adanya kerusakan organ, kelainan pertumbuhan seperti bengkok pada tangkai daun, kekurangan nutrisi yang dapat mengakibatkan pemudaran warna pada daun, terbebas dari OPT dan residu pestisida serta adanya pretreatment dengan merendam tangkai daun dengan air yang

Tabel 5. Standar perusahaan untuk kriteria panen dan pascapanen daun potong

\begin{tabular}{|c|c|c|}
\hline Tanaman & \multicolumn{2}{|c|}{ Kriteria } \\
\hline & Panen & Pascapanen \\
\hline Asparagus & - Panjang tangkai daun $\geq 35 \mathrm{~cm}$ & - Panjang tangkai daun berukuran \\
\hline Umbellatus & $\begin{array}{l}\text { - Daun berwarna hijau tua } \\
\text { - Batang berwarna coklat } \\
\text { - Batang Kokoh } \\
\text { - Bebas dari kerusakam dan OPT }\end{array}$ & $\begin{array}{l}\text { - } 35 \mathrm{~cm}, 50 \mathrm{~cm} \text {, dan } 70 \mathrm{~cm} \\
\text { - Tidak ada daun yang berwarna hijau } \\
\text { muda atau kuning } \\
\text { - Bebas dari kerusakan } \\
\text { - Batang berwarna coklat dan kokoh }\end{array}$ \\
\hline Monstera & $\begin{array}{l}\text { - Panjang daun } 20 \mathrm{~cm} \text { dan panjang tangkai } \\
\text { daun } 50 \mathrm{~cm} \\
\text { - Daun berwarna hijau tua } \\
\text { - Bebas dari kerusakam dan OPT }\end{array}$ & $\begin{array}{l}\text { - Panjang tangkai daun minimal ukuran } 45 \\
\text { cm dan maksimal } 70 \mathrm{~cm} \\
\text { - Daun berwarna hijau tua } \\
\text { - Bebas dari kerusakan } \\
\text { - Terbebas dari OPT }\end{array}$ \\
\hline Philodendron & $\begin{array}{l}\text { - Panjang daun berdiameter } 15 \mathrm{~cm} \text { dan } \\
\text { panjang tangkai daun } 45 \mathrm{~cm} \\
\text { - Daun berwarna hijau tua } \\
\text { - Bebas dari kerusakam dan OPT }\end{array}$ & $\begin{array}{l}\text { - Panjang tangkai daun minimal ukuran } 45 \\
\text { cm dan maksimal } 70 \mathrm{~cm} \\
\text { - Daun berwarna hijau tua } \\
\text { - Bebas dari kerusakan } \\
\text { - Terbebas dari OPT }\end{array}$ \\
\hline
\end{tabular}

Keterangan : Data perusahaan Kwekerij Figaro tahun 2018

memiliki minimal panjang tangkai $35 \mathrm{~cm}$ karena berfungsi sebagai filler yaitu pengisi rangkaian bunga yang membutuhkan tinggi tangkai tidak terlalu pendek yang bertujuan untuk memudahkan proses pengangkutan dan sortasi. Kriteria pemilihan pada ketiga komoditas setelah tahap pemanenan akan dikelompokkan berdasarkan ukuran. Pada tahap ini pekerja harus bekerja dengan cepat dan tepat agar dapat menyelesaikan target produksi yang sudah ditentukan oleh perusahaan setiap harinya.

\section{Perbedaan Jumlah Panen dengan Rata-Rata Standar Perusahaan}

Perbedaan jumlah panen dengan rataan panen harian dapat mempengaruhi waktu panen yang menyebabkan bertambahnya waktu kerja bagi pekerja (Tabel 6). Pengamatan dilakukan dengan mengambil 4 kali ulangan pada tanaman Asparagus umbellatus, Monstera dan Philodendron. Perusahaan memiliki standar produksi yang berubah-ubah setiap harinya tergantung permintaan dari konsumen.

\begin{abstract}
mengandung zat aktif Natrium dichloroisocyanurate untuk vaselife (VBN, 2018).
\end{abstract}

Kriteria pemanenan yang paling utama pada ketiga komoditas yang dibudidayakan di greenhouse yaitu daun berwarna hijau tua dan memiliki panjang tangkai minimal $35 \mathrm{~cm}$. Daun

- Terbebas dari OPT

Berdasarkan Tabel 6. perbedaan jumlah panen dengan rataan panen harian didapat melalui jumlah pekerja di perusahaan dikalikan dengan rata-rata panen setiap harinya, hasil yang didapat lalu dikurangi dengan standar panen perhari di perusahaan. Jumlah pekerja tetap di greenhouse yaitu 3 orang, jumah pemanen pada ketiga komoditas berbeda sesuai dengan produksi yang dibutuhkan setiap harinya, pemanen Asparagus umbellatus lebih banyak dibanding dengan tanaman Monstera dan Philodendron. Didapat persen perbedaan jumlah panen dengan rataan panen pada ketiga komoditas yang diamati adalah $<10 \%$, diartikan bahwa perbedaan jumlah panen tidak terlalu tinggi itu terjadi karena proses panen dilakukan dengan tepat cara sehingga meminimalkan perbedaan jumlah tanaman yang dipanen dengan rata-rata standar panen perhari. Perbedaan panen dapat terjadi pada tanaman yang tidak sesuai dengan kriteria yang ditetapkan oleh perusahaan akibat dari kesalahan memotong yang disebabkan oleh kecepatan pekerja dalam memanen. 
Tabel 6. Standar perusahaan untuk kriteria panen dan pascapanen daun potong

\begin{tabular}{lccccc}
\hline Tanaman & $\begin{array}{c}\text { Rata-rata } \\
\text { Standar } \\
\text { Panen Per- } \\
\text { hari } *\end{array}$ & $\begin{array}{c}\text { Rata-rata } \\
\text { Panen } \\
\text { Per- hari } \\
* *\end{array}$ & $\begin{array}{c}\text { Jumlah } \\
\text { Pekerja } \\
*\end{array}$ & $\begin{array}{c}\text { Jumlah } \\
\text { Panen } \\
\text { Per- hari } \\
* *\end{array}$ & $\begin{array}{c}\text { Perbedaan Jumlah } \\
\text { Panen dengan Rataan } \\
\text { Panen Harian } * *\end{array}$ \\
\hline Asparagus umbellatus & 3503 & 1045 & 3 & 3180 & $9.3 \%$ \\
\hline Philodendron & 984 & 918 & 1 & 918 & $6.7 \%$ \\
\hline Monstera & 1520 & 702 & 2 & 1404 & $6.4 \%$ \\
\hline
\end{tabular}

Keterangan: *: Data sekunder arsip perusahaan pada tahun 2017 , **: Data pengamatan penulis

Rubel. 2006. World map of Koppen-Geiger climate classification updated. Meteorol Z. 3(15): 259-263.

\section{KESIMPULAN}

Pengelolaan panen dan pascapanen tanaman hias daun yang diamati di lokasi penelitian (greenhouse) sudah dilakukan dengan baik. Hal tersebut ditunjukan dengan pevourrsen perbedaan jumlah panen dengan rata-rata standar panen perhari yaitu $<10 \%$.

\section{DAFTAR PUSTAKA}

[BALITHI] Balai Penelitian Tanaman Hias. 2008. Monstera deliciosa Liemb. http://balithi.litbang.pertanian. go.id/berita68-monstera-deliciosa-liemb.html [26 Desember 2017].

[BBC] British Broadcasting Corporation. 2014. Netherlands country profile. Economics of greenhouse. www.bbc.co.uk. Desember 2017].

[GAIN] Global Agriculture Information Network. 2016. The Netherlands Horticulture Market. USDA Foreign Agricultural Service. Netherlands.

[VBN] Vereniging van Bloemenveilingen in Nederland. 2018. Productspecificatie. https://beheer.vbn.nl Zoekscherm/Products pecificatie.aspx ?lang $=$ NL\&specid $=100697 \&$ type=part\#b2. [20 Juli 2018].

Heesen, M.R. 2011. Verkennend Bodemonderzoek Naaldjwik Ongenummerd te Poederoijen. NIPA Milieutechniek B.V. Lanweerstraat.

Kottek, M., J. Grieser, C. Beck, B. Rudolf, F.
Roseita, B. 2012. Research On The Foliage Industry. Irish Foliage Committee. USDA. Netherlands.

Santoso, B.B. 2003. Penanganan pascapanen bunga potong dan tanaman hias pot. Fakultas Pertanian, Universitas Mataram.

Siong, Budiana.2008. 87 Philodedendron Tampil Menawan. Penebar Swadaya. Jakarta.

Talbott, L.D., E. Rahveh. E. Zeiger. 2003. Relative humidity is a key factor in the acclimation of thestomata response to $\mathrm{CO} 2$. Journal of Experimental Botany. 54(390):2141-2147.

Tono. 2002. Analisis preferensi konsumen terhadap atribut tanaman hias dalam ruangan (indoor plants) di Kota Bogor. [Skripsi]. Institut Pertanian Bogor. Bogor.

Vourdoubas, J. 2015. Overview of heating greenhouses with renewable energy souces case study in crete-greece. Journal of Agriculture and Environmental Sciences. 4(1):70-76.

Weerstation Westland. 2017. Temperatuur overzichten $\left({ }^{\circ} \mathrm{C}\right)$. http://www.westlanddepoel.nl/vantagevue/ws/ wxtempsummary.php?. [15 Juli 2018].

Winda, E.R. 2006. analisis strategi pemasaran tanaman hias daun dalam pemanfaatan sebagai daun potong ada pesona daun mas asri, Ciawi Kabupaten Bogor. [Skripsi]. Institut Pertanian Bogor. Bogor. 